\title{
Electronic Informed Consent: effects on enrolment, practical and economic benefits, challenges, and drawbacks. Studies within Randomised Controlled Trials. Systematic Review.
}

Ana Teresita Mazzochi ( $\nabla$ teremazzochi@gmail.com)

The University of Edinburgh https://orcid.org/0000-0003-2117-6112

Martin Dennis

The University of Edinburgh

Ho-Yan Yvonne Chun

The University of Edinburgh

\section{Research Article}

Keywords: electronic informed consent, enrollment, SWAT, randomized controlled trials, systematic review

Posted Date: February 10th, 2022

DOI: https://doi.org/10.21203/rs.3.rs-1269685/v1

License: @ (i) This work is licensed under a Creative Commons Attribution 4.0 International License. Read Full License 


\section{Abstract \\ Background}

Enrolment is one of the most challenging aspects of conducting clinical trials, preceded by the process of informed consent (IC). Different strategies to improve recruitment in clinical trials have been used, including electronic IC. During COVID-19 pandemic, barriers to enrolment have been evident. Although digital technologies were acknowledged as the future of clinical research and potential advantages were shown for recruitment, electronic informed consent (e-IC) has not yet been globally adopted. The purpose of this review is to investigate the effect of using e-IC on enrolment, practical and economic benefits, challenges, and drawbacks when compared to traditional informed consent, through a systematic review.

\section{Methods}

Embase, Global Health Library, Medline, and The Cochrane Library databases were searched. No limit was set for publication date, age, sex, or study design. We included all studies within a randomised controlled trial (RCT), published in English, Chinese or Spanish, evaluating the electronic consent process used in the parent RCT. Studies were included if any of the three components (i. information provision, ii. participant's comprehension, iii. signature) of the IC process was designed as electronic, whether administered remotely or face-to-face. The primary outcome was the rate of enrolment to the parent trial. Secondary outcomes were summarised according to the various findings reported on the use of electronic consent.

\section{Results}

From a total of 9069 titles, 12 studies were included in the final analysis with a total of 8864 participants. Five studies of high heterogeneity and risk of bias showed mixed results on the efficacy of e-IC on enrolment. Data of included studies suggested e-IC could improve comprehension and recall of study-related information. Meta-analysis could not be conducted due to different study designs and outcome measures and the predominantly qualitative findings.

\section{Conclusion}

Few published studies have investigated the impact of e-IC on enrolment and findings were mixed. e-IC may improve participant's comprehension and recall of information. High quality studies are needed to evaluate the potential benefit of e-IC to increase clinical trial enrolment.

\section{Trial registration:}

International Prospective Register of Systematic Reviews (PROSPERO CRD42021231035)

\section{Introduction}

Enrolment is known to be one of the most challenging aspects of conducting clinical trials (1-3). Enrolment is preceded by the process of informed consent (IC), during which an effective communication of trial information is crucial before obtaining a participant's IC on trial participation (4).

IC is the first trial process to ensure that potential participants are duly informed of the trial involvement, and that their decision to participate is voluntary and should be free of undue influence, incentive, or coercion (5). Large-scale societal lockdowns as a response to the severe acute respiratory syndrome corona virus 2 (SARS-CoV-2) pandemic in 2019 directly impacted on the execution of clinical trials due to restrictions imposed on in-person visits. The halt in trial activities in turn brought about the emergence of digital health technologies as a viable solution for consenting and recruiting trial participants. While some aspects of electronic informed consent (e-IC) have been researched and tested in fully remote trials pre-pandemic (6), there is a stronger demand for further evaluation of e-IC as the global health emergency has re-positioned decentralized or remote clinical trial methods (e.g., web-based trials) as the favored approach for conducting clinical research.

Enrolment

Enrolment can be defined as a person's agreement to participate in a clinical trial. The person's decision on whether to take part in a clinical trial or not, has underlying implications on the validity of a trial. Sample size recruited should provide sufficient statistical power in the trial data to enable precise measurement of study endpoints. Under-recruitment jeopardizes the internal validity of the trial with imprecise results. Evidence has shown that less than onethird of trials achieve their original planned sample size in time (7). Sample recruited to a trial needs to be representative of the target population for its results to be externally valid. Enrolment methods need to minimise the degree of selection bias. Geographical location, disability of potential participants and complexity of the IC process are example barriers to accessing clinical research opportunities.

\section{Electronic Informed Consent}

e-IC is defined as "the use of any electronic media (such as text, graphics, audio, video, podcasts or websites) to convey information related to the study and to seek and/or document IC via an electronic device such as a smartphone, tablet or computer" (8, pp. 4). Potential benefits in using e-IC when compared to using paper consent include improved information provision with multimedia content, improved access to research, removing the need for travel for potential participants or research staff, which could ultimately enhance trial recruitment (9). Potential drawbacks include the difficulty in determining a person's 
capacity or if the consent was informed or voluntary, the risk of identity theft and issues around data confidentiality $(10, \mathrm{pp} .218,11,12)$. IC is a complex process that can be divided into three components: i) information provision, ii) a participant's comprehension assessment and iii) obtaining a valid signature (13).

\section{i) Information provision}

Fully disclosing all the elements contemplated in ICH-GCP (14, pp. 24) can be cumbersome and it is linked to the training, knowledge, and ability of the clinical researcher to express difficult concepts in understandable words in order to ensure that the person is fully informed to take a free and voluntary decision. Too much information may be detrimental to the person's understanding while others may consider it a breach of person's rights when too little information is provided $(15,16)$.

\section{ii)Participant comprehension assessment}

Comprehension can be affected by a number of different factors such as: the capacity of the researcher to effectively communicate with the potential participant, the amount of time dedicated to the process of providing information and assessing comprehension, the level of literacy of the potential participant and/or legal representative, the health condition of the potential participant that may reduce their capacity to understand, and the readability and/or layout of their document (17). The assessment of information comprehension may become a challenge when the IC process is carried out remotely. Methods should be in place to ensure potential participant has adequate understanding of the information given before consenting to the trial.

\section{iii) Obtaining a valid signature}

ICH-GCP guidelines state that both the potential participant/legally acceptable representative (LAR) and the person who conducted the IC discussion, should sign, and personally date the written IC form (14, section 4.8.8). The introduction of web technologies in clinical research has brought about the possibility of replacing wet-ink signature with electronic signature. The U.S. Food and Drug Administration (FDA) (18) guidance considers electronic signature equivalent to full handwritten signature when it complies with the Code of Federal Regulations (18, pp. 7). In the United Kingdom, the Joint Statement on Seeking Consent by Electronic Methods, distinguishes between different types of electronic signature and considers different scenarios when deciding which type of signature is best to adopt (8). Privacy and data protection concerns have limited the use of electronic signature for IC in other countries (19).

Rationale for this review

\section{Evidence before this review}

The PRioRiTy trial, a study which identified research priorities for how to improve the process of recruitment and retention in RCT (20), has acknowledged IC optimization as an area that requires further research to improve enrolment. While systematic reviews on strategies to improve recruitment to randomised trials have been conducted, they did not focus on e-IC as the intervention $(21,22)$. Other reviews that analyzed the impact of digital tools on recruitment were not related to the process of IC $(23,24)$ or were solely aimed at the first component (information provision) of the IC process being administered electronically $(25)(26)$.

\section{Potential impact}

Regulatory agencies and various private-public partnerships (27-29) have acknowledged the vital role played by digital technologies in the future of clinical research, recognizing the potential advantages they bring to recruitment and process quality. In spite of this, e-IC has not yet been globally adopted (30). A systematic review is necessary to summarise the latest evidence on the process of e-IC as a key step in improving the process of IC and enrolment to clinical research.

Aim

The overarching aim is to investigate the effect of e-IC on enrolment, practical and economic benefits, challenges, and drawbacks of using e-IC when compared to traditional IC, through a systematic review.

\section{Research Questions}

1) Does the use e-IC (any of the three components) improve enrolment rate: proportion of invited potential participants enrolled and/or number of participants recruited in a given period (e.g. month)?

- The three components of the consent process are: i) information provision, ii) assessment of participant's comprehension and iii) the signature process.

2) To summarize available research findings, including qualitative information on the use of e-IC (any of the three components): the practical and economic benefits and challenges, drawbacks, acceptability by patients, feasibility e.g. failure to complete consent process thus needing to switch over to paper consent, and other findings that the author may find relevant during this review.

\section{Methods}

\section{Ethical considerations}


This project was not submitted for considerations by research ethics committee.

\section{Protocol}

This systematic review was reported according to the Preferred Reporting Items for Systematic Reviews and Meta-Analyses (PRISMA) statement (31). The study protocol is registered in the International Prospective Register of Systematic Reviews (PROSPERO CRD42021231035). PRISMA Checklist was completed and is available with the Protocol in Additional File - Appendix 1.

\section{Information Sources and Search Strategy}

We searched the electronic databases Embase, Global Health Library, Medline, and The Cochrane Library for potential studies. The search strategy was built upon prior systematic reviews to identify key search structures and terms such as "informed consent", "clinical trials", "electronic informed consent" and a search string was developed for Embase database consisting of Medical Subject Heading (MeSH) and text words. Search string was adapted to the rest of the databases to account for search syntax, metadata, and platform functionality. All search strategies were reviewed by a health science librarian with expertise in systematic reviews searching. We searched all published and recently completed, and yet to be published studies, and reference lists of relevant systematic reviews from inception to 11 January 2021 in English, Chinese and Spanish. The full search strategy for all databases can be found in Additional file -

Appendix 2.

\section{Inclusion criteria}

We included studies of all ages and sex that evaluated a consent method within a randomised controlled trial setting (Study Within a Trial - SWAT) (32). SWATs are defined as "a self-contained research study that has been embedded within a host trial with the aim of evaluating or exploring alternative ways of delivering or organizing a particular trial process" (32, pp. 1). SWATs are considered the most suitable study design to increase the evidence base for e-IC processes(32).

\section{Type of Participants}

Male and female with no age limit.

\section{Type of Interventions}

One of the three components of IC process i) information provision, ii) assessment of participants' comprehension, iii) signature must be electronic, whether conducted remotely or face-to-face.

Type of Comparator

Traditional IC-paper information and consent form

Type of Outcome measures

- Primary Outcome:

- Rate of enrolment (defined as the proportion of invited potential participants enrolled and/or the number of participants recruited in a given period (e.g., month).

- Secondary Outcomes:

A narrative summary of information on the use of e-IC including:

- Effects on the economic cost of using e-IC compared to traditional IC

- Practical benefits and challenges of implementing e-IC, acceptability to potential participants, feasibility e.g. failure to complete consent process thus needing to switch over to paper consent and other findings on user experience reported on the use of e-IC.

\section{Exclusion criteria}

Book reviews, conference notes, editorials, letters to the editor and abstracts not accompanied by a full text were excluded (Additional File - Appendix 3 ).

\section{Study Selection}

All titles and abstracts were imported to ENDNOTE X9 reference manager and duplicates were removed. The resulting references were uploaded to Covidence Systematic Review manager (33), and further duplicates detected by the system were automatically removed. Titles and abstracts were screened by one reviewer to select studies that fulfilled the eligibility criteria. Full texts were obtained for the short-listed studies and were assessed for final inclusion by two reviewers. For those cases where full text was not available, one attempt was made to contact the authors. Disagreements on whether to include a study were discussed between reviewers and resolved by consensus. Reasons for study exclusion at the full-text stage were recorded and information was summarized using the PRISMA Flow diagram (34). Additional studies were hand searched by reviewing the reference lists of included studies.

\section{Risk of bias of included studies}


Cochrane risk of bias assessment (35) was performed for each included clinical trial. Risk of bias was assessed on sequence generation, allocation concealment, blinding of participants and personnel, blinding of outcome assessment, incomplete outcome data and selective reporting. Studies were rated as "high risk", "low risk", or "unclear risk" and a graphic representation and summary was provided for all included studies. Risk of bias assessment for all Cohort and Case Controlled studies was performed using the Critical Appraisal Skills Programme (CASP) (36) checklist. Risk of bias assessment was performed by one reviewer and verified by a second reviewer. In case of disagreements, consensus was reached by discussion. The potential influence of any risk of bias on the review findings was described.

\section{Data Extraction}

Data extraction of selected studies was supported by Covidence Systematic Review Manager, independently performed by one reviewer and verified by a second reviewer. Disagreements were resolved by discussion between the two reviewers. For each included study, data were extracted on the lead author, country in which the study was conducted, study characteristics including design of the SWAT, health topic, health care setting, publication year, sample characteristics including age, sex, inclusion and exclusion criteria, recruitment method into the parent trial -face to face, telephone or online, total number of participants, type of intervention (which component of the IC process was electronic), type of comparator, outcomes, method of outcome assessment, reported findings. Further narrative information was summarized if it was felt to be relevant to the secondary objective of this review. Data extracted were exported to Excel and Review Manager 5.3 for analysing. For studies that had missing data, authors were contacted. A maximum of three email attempts were performed.

\section{Data Analysis and Synthesis}

A meta-analysis of the quantitative data could not be conducted due to the variety of study designs, comparators, and outcome measures. For the primary outcome, quantitative data were summarized descriptively. For the secondary outcomes, as these were not consistently reported by all studies, reviewers categorized study findings and summarized any relevant results descriptively and narratively. SWiM guidelines stated in the protocol could not be used as they are not intended for use in reviews that synthesize qualitative data (37). Data analysis was performed by one reviewer and verified by the second reviewer using a narrative synthesis approach with thematic summary (38).

\section{Risk of bias across studies}

We planned to assess the overall certainty of evidence of each outcome with the GRADE system, but this could not be done as data could not be pooled. In addition, the main purpose of this systematic review was to summarize the available findings. It was not under the authors' scope to make recommendations.

\section{Results}

\section{Study Selection}

The search strategy conducted in all four databases retrieved 9069 records which were imported to Covidence for title and abstract screening. Duplicates were automatically removed by the system. From the resulting 8355 records, a total of 286 references were included in full-text review. Two reviewers assessed the articles independently. The first reviewer assessed 286 articles, and the second reviewer assessed 192 articles (94 remaining articles at full-text stage were assessed only by one reviewer). Twelve studies were included in the final analysis. Study selection and reasons for exclusion are shown in the Study Flow diagram in Figure 1. Expanded table of all included studies is shown in Additional File - Appendix 4.

\section{Study Characteristics}

A summary of the main characteristics of included studies is shown in Table 1.

TABLE 1 SHOULD BE INSERTED HERE

\section{Study Design and Country}

From a total of 12 included studies, six were conducted in the United States (39-44), two in the United Kingdom (45, 46), one each in Gambia (47), Uganda (48), Canada (49), and one, conducted globally, reporting results from 23 different countries (50).

Study design of all included studies were SWAT, i.e., studies within parent RCTs. Six studies within trials were RCTs $(40,41,45-47,49)$ and six were observational studies $(39,42-44,48,50)$.

\section{Health Topic and Setting}

Parent studies of included trials addressed different health topics such as depression ( 2 studies), infectious diseases ( 3 studies), stroke ( 1 study), prenatal education ( 1 study), chronic obstructive pulmonary disease (COPD) (1 study), spine surgery ( 1 study), breast cancer ( 1 study), prelabour rupture of membranes ( 1 study) and prevention of behavioral problems in young children (1 study). Health care settings varied from hospitals, remote community, outpatient clinics, community-based clinics, general practices, physician's offices and patient's homes. All studies were published between 2005 and 2020 , except one that was published in 1997 (49).

\section{Study Participants}

Studies varied in their participants' characteristics as they targeted selected groups (Table 1). Mean age was reported in 10 studies, ranging from 27 to 73 years $(39-46,49-50)$. Two studies did not provide mean age of participants (47-48). Six studies included men and women $(39,41-43,45,47)$. Four studies 
included only women $(40,48-50)$. One study did not exclude men in its criteria but represented only female perspective (44) and another study included parents aged $\geq 18$ years with child aged between approximately 12 and 36 months (46).

Level of education was reported in nine studies, with three reporting no formal education in the majority of their sample $(45,47,48)$. The remaining six studies reported educational level ranging from university to college education (40) (43-44) (46) (49-50).

\section{Recruitment method}

Eight of the 12 studies reported their method of recruitment of participation as face-to-face. Other studies reported methods of recruitment were by phone (39, 42), online (50), and by phone and letter (45).

\section{Sample Size}

In total, 8864 people participated in the 12 included studies. Number of participants analyzed per individual study ranged from four to 4214 .

\section{Type of Intervention and Comparator}

\section{Intervention type by IC component:}

Nine out of the 12 included studies only evaluated the first component of the IC process, i.e., electronic information given to trial participants. In these studies, electronic information was provided in different ways, for example, as an aid to the paper IC form $(40,41,43,45,46,49)$ and as standalone electronic information $(44,47,48)$. Formats for providing information varied from multimedia tool, slide show, video, and telemedicine (computer-enabled audio-visual communication). Three studies $(39,42,50)$ had all three components of the IC form carried out electronically. No studies evaluated an intervention pertaining to only the second component of IC: participant comprehension. When electronic components of IC were provided, they were done both remotely $(39,42,45$, 46) and on-site/face-to-face (40, 41, 43, 44, 47-49).

\section{Comparator}

Traditional IC (face-to-face information and paper written consent) was the pre-defined comparator in this systematic review. Eight studies had traditional IC $(39-42,45-46,47,49)$ as the comparator. Other comparators were used in two studies: standard information read out by researcher (48) and pre- and postintervention comparison in patient's preference $(43)$. Two studies $(44,50)$ did not include a comparator.

Most studies with a comparator included two arms. One trial (48) included three arms. All comparisons are listed as follows:

First component of IC (electronic information giving):

1. Video information vs written versions in local languages or verbal presentation of the written IC given by trained study staff who were native speaker of the local language (47)

2. Slideshow using illustrated text on a flip chart vs video vs standard researcher-read information (48)

3. Video as an aid to paper IC vs written IC $(40,46)$

4. Telemedicine (computer-enabled audio-visual communication) as an aid to paper consent vs written IC (41)

5. Written IC with access to a multimedia information resource vs written IC (45)

6. Video decision aid as part of their IC process (before and after comparison in treatment preference) (43)

7. Video vs written IC (49)

8. Educational video vs no comparator (44)

All three components of IC were electronic

1. Automated online IC vs no comparator (50)

2. Videoconferencing vs written IC in person (42)

3. Online IC vs written IC(39)

\section{Study Outcomes}

Five studies (44-46) provided data on the primary pre-defined outcome-rate of enrolment. For the secondary pre-defined outcomes, one study described the economic cost of using e-IC but none reported quantitative outcomes on the practical benefits or challenges of implementing e-IC. There was narrative information reported on the acceptability to potential participants. There were outcomes reported by studies that were not anticipated in the protocol: participant's comprehension of information, effect on changes in treatment preferences by participants, experience of e-IC by users, participant and researcher attitudes towards method of recruitment, number of participants responding to the trial invitation, intention to participate in a clinical trial, and retention rates. Outcomes were varied and were measured in different ways. Some studies utilized questionnaires administered through computers, surveys sent by emails, electronic multiple-choice options, and in-person or telephone interviews.

Summary of outcomes is shown in Table 2. 


\section{Quality Assessment}

The quality of included studies varied. All six RCTs included in this review $(40,41,45-47,49)$ were assessed using the Cochrane Risk of Bias tool, and overall, they were judged to be at moderate-to-high risk of bias. Graphical summary of the risk of bias of included RCTs are shown in Figure 2 and Figure 3 . Complete assessment of risk of bias using the Cochrane risk of bias table is detailed in Additional File - Appendix 5 and 8.

The assessment of risk of bias for non-randomised studies was performed using the CASP checklist (36). Templates for the Case Control and Cohort risk of bias are available in Additional File - Appendix 6 and 7. Overall, studies were judged as high risk of bias as there was not sufficient information to perform a detailed assessment. There were a mixture of secondary analyses, case control studies, cohort studies and studies that lacked objective outcome measures (Additional File - Table 3 and Appendix 8).

\section{Primary Outcome}

Five studies provided data on the predefined primary outcome - rate of enrolment, defined as the proportion of invited potential participants enrolled and/or the number of participants recruited in a given period (e.g., month).

\section{Effect on Recruitment Rate}

Two studies showed no statistically significant improvement in recruitment rate following an intervention when compared to written IC as controls. These interventions were written IC with access to a multimedia resource [OR $0.84,95 \% \mathrm{Cl} 0.58$ to 1.22 ] (45) and computer-enabled audio-visual communication as an aid to paper consent [ $56 \%$ vs. $69 \%, p=0.142](41)$.

One study showed that an intervention group using a video aid to paper ICF was less likely to take part in the main clinical trial when compared to written IC $(\mathrm{OR}=0.25, \mathrm{Cl}=0.10-0.62, \mathrm{p}=0.003)(46)$.

Weston et al. showed a significantly larger proportion of participants expressing willingness to participate in a future trial when they have received the video intervention compared to those that received written IC $(61.9 \%$ vs. $35.4 \%, x 2=6.3 ; d f=1 ; P=0.01)(49)$. Swain et al. showed that a video intervention resulted in a statistically significant increase of participant enrolment to a clinical trial by $7 \%$ post-intervention when compared to the enrolment rate pre-intervention in a previous year (13.5\% of 200 participants enrolled post-intervention, $6 \%$ enrolled pre-intervention, $\mathrm{p}<0.001)(44)$.

\section{Secondary Outcomes}

\section{Economic costs}

Jolly et al. (45) estimated an additional six people would be recruited per 1000 approached at a cost of $£ 100$ per additional patient with the use of an online multimedia intervention which consisted of study-specific information, generic information on e.g., confidentiality, informed consent, randomization and videos of participants' experiences. The cost of the online multimedia intervention was estimated $£ 2500$ ( 45 , pp. 4). We contacted the authors for the paper by Afolabi et al (47), which stated the economic summary of their multimedia intervention was available by correspondence. No reply has been received at the time of writing this report.

\section{Other secondary outcomes}

The predefined secondary outcomes relating to the practical benefits, challenges of implementing e-IC, and acceptability of e-IC to potential participants were not universally reported by all of the studies. Some studies reported findings relevant to these outcomes, so we have provided a descriptive and narrative summary of what we felt were relevant to these outcomes.

\section{Patient Comprehension and Understanding}

Five studies $(40,41,47,48,50)$ measured patient's comprehension and understanding of the information as their primary outcome.

Afolabi et al. (47) reported better comprehension of study information, measured using an IC comprehension questionnaire, at baseline, day seven and day 14 in the group that received video information when compared to the group that received written versions in local languages or verbal presentation of the written IC by trained native language-speaking staff (score at day $14: 64 \%$ v $40 \%, p=0.035$ ). Barrera et al. (50) reported that, with the use of an automated IC process for an online trial, a high proportion of participants $(n=1,179)$ showed a correct understanding of the study's purpose $(86.1 \%)$ and correctly identified two of three of the study's benefits (74.6\%). 56\% correctly identified some or all of the potential risks of participation (50, pp. 5). Rothwell et al. (40) found that using a video presentation on an iPad, followed by a paper copy of the consent form may improve understanding of some aspects of a trial: "the alternatives to participation in this study" ( $4.88 \pm 0.42$ vs. $4.37 \pm 1.10, p=.047)$; "who to contact if you are upset because of participation in this study" ( $4.41 \pm 0.80$ vs. $4.03 \pm$ $1.40, p=.002)$; "Whom you should contact if you have questions or concerns about this study" ( $4.34 \pm 0.97$ vs. $4.13 \pm 1.33$, $p=.009)$; and "Overall, how well did you understand this study when you signed the consent form" ( $4.72 \pm 0.58$ vs. $4.63 \pm 0.67, p=.019)(40$, pp. 5$)$. Qualitative interviews in this study supported that the video was easy to understand and improved participants' attention.

Bobb et al. (41) found that comprehension of consent using telemedicine (computer-enabled audio-visual communication as an aid to paper consent) was not inferior to standard face-to-face written consent, measured using a modified quality of informed consent instrument (QuIC) (QulC scores $74.4 \pm 8.1$ vs. $74.4 \pm$ 6.9 on a 100-point scale, $p=0.999)$. 
Ditai et al. (48) reported no statistically significant difference on the QuIC tool at 48 hours after consenting to any of the three models of IC: i) Slideshow using illustrated text on a flip chart, ii) an approved study video iii) standard researcher-read information. Most participants in this study preferred the slide-show message $(63 \%, 19 / 30)$, compared with $20 \%(6 / 30)$ for the video message and $17 \%(5 / 30)$ for the standard model.

Weston et al. (49) found no differences in knowledge about the perinatal trial after receiving a video intervention when compared to written IC but they did find an increase in the retention of knowledge $2-4$ weeks later by women in the video intervention group.

Acceptability to participants and user experiences

Mattock et al. (46) reported positive feedback on the usefulness of a video aid in addition to paper IC in all participants. All 17 participants interviewed found information easy to understand and informative but also commented on additional questions that needed discussing over the phone. Participants in the video group described material as introductory whilst those in standard consent group described the standard information as comprehensive. Participants and researchers found that an initial email contact increased participant's receptivity to the study and engagement in the trial. Researchers also reported a better understanding of randomization by participants who watched the video.

Haussen et al. (39) reported acceptability of the use of an entirely electronic IC process to remotely obtain IC from the legally authorized representative (LAR) of stroke patients being enrolled into a clinical trial of neurointervention-the DAWN trial (39, pp.1). The LARs surveyed in this study reported no reservation in using this e-IC process via Research Electronic Data Capture (REDCap) platform, a secure/Health Insurance Portability and Accountability Act compliant data management platform, developed by the Vanderbilt University. This was used to create an online IC form, which could be accessed on a webpage. The investigator held discussion with the LAR of the potential participant over the telephone. Once agreed to be enrolled, LAR was sent a text message with a link to the webpage to complete the online IC form, which had the capability of capturing the LAR's electronic signature.

Bobb et al. (41) identified no significant barriers in the use of telemedicine (computer-enabled audio-visual communication) as an aid to paper consent from its qualitative survey. It reported that video was easy to understand and was better at holding patient's attention than a paper-based approach would have.

\section{Other Outcomes}

\section{Changes in treatment preferences}

Lurie et al. (43) found that watching video information prior to enrolment to a clinical trial comparing surgical and non-surgical treatments for spinal diseases led to a shift in treatment preference compared to non-watchers $(37.9 \%$ vs $20.8 \%, p<0.0001)$. These shifts were balanced and did not demonstrate any overall shift towards or away from surgery.

\section{Invitation response and retention rates}

Jolly et al. (45) found no effect on the proportion of people responding to study invitation (OR $=1.02,95 \% \mathrm{Cl} 0.79$ to 1.33 ) or retention in the trial at 6 (ORs $0.84,95 \% \mathrm{Cl} 0.57$ to 1.22 ) and 12 months after randomisation with the use of a multimedia information resources as an addition to written IC when compared with written IC only (ORs $0.80,95 \% \mathrm{Cl} 0.54$ to 1.18$)$.

Study by Swain et al. (44) showed an increase of $14 \%(p<.001)$ in the proportion of patients expressing likelihood to enroll in a trial for breast cancer after the use of an educational video in a survey of attitudes and intention to enroll in therapeutic clinical trials.

\section{Assessing intervention fidelity}

Jolly et al. (45) did not report the number of participants who used the link to access the multimedia resource which was part of the intervention, so it was unclear how many participants actually used the resource.

Study by Mattock et al. (46) utilized an entirely remote e-IC process to obtain IC from LAR. However, it was not possible to ascertain whether the LAR actually read the online IC. It was unclear how much time the LARs or patients were given to decide about trial participation.

\section{Discussion}

The objective of this systematic review was to investigate the effect of e-IC on enrolment and summarize available research findings on its use. This review has demonstrated that evidence is heterogeneous with varying intervention designs and target populations and disease groups. Narrative synthesis reported inconclusive findings on the impact of the use of electronic consent on enrolment with two of five trials reporting a benefit. We were unable to pool data on the primary outcome as studies had different study designs, comparators and were aimed at different population. Studies were of small sample size, had unclear allocation concealment, blinding with high risk of bias. The findings from these studies might have limited generalizability as studies that measured the primary outcome were conducted in high-income countries, where access to computers, cell phones and internet is more feasible. Most of the included studies investigated the first component of the IC process, i.e., information given to trial participants. Only three studies evaluated all three components of the IC process.

\section{Secondary Outcomes}

Patient Comprehension and Understanding 
Many studies reported on participant's comprehension and recall of information. Though sample sizes, design, population, and interventions varied (some interventions were entirely electronic, and others were done as an aid to traditional paper consent, and some of them were administered in person and others remotely), studies described improvement on the use of electronic information on participant's comprehension and recalling of information. These findings are consistent with findings from another systematic review (25). Apart from the five studies measuring comprehension and understanding, two additional studies $(45,46)$ commented on the benefits regarding accurate recalling of study specific details (what the study was about, benefits and participant's assignment to different study groups) and a better understanding for all participants in the electronic consent group. Effect on comprehension was of particular interest to studies that included participants from a population that had little or no formal education. These studies showed that for people who were unable to read or write, audio-visual interventions had major positive effects on understanding and recalling. Given the positive findings reported, more studies testing the effect of electronic information without additional aids could be of great interest for the conduct of fully virtual trials.

\section{Other outcomes}

Acceptability of intervention, practical challenges and patient experiences were reported in a variety of ways by these studies, mainly narratively. Promising feedback on e-IC has been obtained but overall, there was insufficient evidence to enable conclusions to be drawn on patient and/or research staff's satisfaction on the entire process of e-IC. None of the interventions specifically aimed to assess the second component of the IC process (participant comprehension) and third component of the e-IC process (IC signature). Assessing these specific components could provide further valuable information, especially as there were concerns reported by some participants on the need to interact with research staff to clarify doubts or raise more questions on the information that was provided to them by electronic means.

Strengths and limitations of the systematic review and narrative synthesis

This review was a comprehensive and systematic review of the literature, conducted according to the current CONSORT guidelines for the development of its protocol. This protocol of this review was registered in the PROSPERO database. The search strategy was based on prior reviews addressing electronic consent and included broad search terms with no limitation on the year of publication. Authors were contacted for additional information on summary data where applicable, but no responses were received at the time of writing this review.

\section{Limitations}

Only one author performed title and abstract screening, and due to time constraints, two reviewers independently assessed the full text for only some of the articles, resulting in 94 articles being assessed by only one reviewer. Data extraction and quality assessment was also performed by one reviewer and verified by the second one, but this process was not carried out independently. The CASP checklist for assessing the risk of bias for observational studies in this review was modified by the author to include a scoring method so as to give an idea of the quality of studies. This scoring method has not been validated.

Strengths and limitations of included studies

Studies were selected through a robust process following the CONSORT guidelines. All selected trials were embedded within a host trial. Although not all studies had a formal protocol as recommended in the guidelines for SWAT (32, pp. 2), they all provided valuable data and lessons that could be used for designing future trials to evaluate e-IC, potentially enhancing the processes of conducting more efficient clinical trials.

Some of the included studies were limited by small sample sizes which could potentially lead to chance findings and unreliable conclusions. Not all included SWATs were randomised controlled trials. Some studies were observational, and others were secondary analysis. The lack of comparators or controls increased the risk of bias from confounders. There was a high heterogeneity noted in study design, the target population, type of intervention and comparator among the included studies. While all studies used some form of electronic consent, not all studies tested it remotely. Many trials reported non-objective outcome measures and mainly qualitative data, making it impossible to perform any meta-analysis. The findings of this review were synthesized narratively, which itself carried the risk of bias in reporting due to variation in how researchers summarize narrative findings.

\section{Implications and future studies}

This review highlights some evidence for improved participant's understanding and recalling of study information with the use of e-IC. A few studies have demonstrated the feasibility of conducting all three components of the e-IC remotely in clinical trials. With the development of technologies and the need to conduct clinical trials more efficiently, e-IC could potentially offer a solution to tackle barriers to enrolment, which have been particularly evident during the COVID-19 pandemic.

Different types of e-IC have been developed, described, and applied (electronic information given to participants in video, multimedia, assessment of comprehension through questionnaires or surveys, electronic signature, electronic consent face to face, electronic consent through telemedicine) and though many of them show advantages over paper consent with regards to comprehension and recalling, the advantages may be specific to the country where it was tested and its associated socio-economic characteristics e.g. lack of access to technology such as internet, computers and mobile phones, lower level of literacy. Findings from these studies thus have limited generalizability for global application. Given the heterogeneity of the included studies, this review highlights the need for future high quality research studies that will evaluate the entire process of e-IC, with detailed description of the three components of the IC process, clearly stated and relevant outcomes such as rate of enrolment, economic benefits, and time taken for e-IC administration. Feasibility of intervention should take into account the characteristics of the target population and the generalizability for the wider population. Qualitative feedback from the investigators and participants could help improve the design for an e-IC process e.g., user interface, logistical challenges. 
Future research of the efficacy of e-IC on recruitment to clinical trials should be built upon robust methodological design, ideally a SWAT that is a clinical trial with suitable comparators to minimize systematic bias. Larger sample sizes are needed to provide sufficient power for precise and reliable conclusions to be drawn on the efficacy of e-IC.

\section{Conclusion}

To our knowledge this is the first systematic review that considers the definition of electronic consent provided by the FDA and MHRA/HRA guidelines, which is inclusive of all three components of the consent process that are conducted electronically. This review aimed to focus on assessing the relationship between electronic consent and enrolment.

We found few published studies have investigated the impact of e-IC on enrolment and findings were mixed. e-IC may improve participant's comprehension and recall of information. The heterogeneity of the studies and their high risk of bias meant that it was not possible to provide definitive conclusions on the efficacy of e-IC on enrolment. This review lays the foundation for future research to focus on high quality studies to evaluate the potential benefit of using e-IC to increase clinical trial enrolment.

\section{Abbreviations}

COPD

chronic obstructive pulmonary disease

COVID-19

coronavirus disease 2019

e-IC

electronic informed consent

FDA

Food and Drug administration

IC

informed consent

ICH-GCP

International Conference on Harmonisation-Good Clinical Practice

LAR

legally authorized representative

$\mathrm{MeSH}$

Medical Subject Heading

QuIC

modified quality of informed consent instrument

RCT

randomised controlled trial

SWAT

studies within a trial

\section{Declarations}

MD has worked with POGO Studio on the development of a web based software package called Tailored Talks which allows clinicians to tailor information to individual patients and to share this digitally. There is interest in using this as part of the electronic consent process in both clinical practice and research. MD has no financial interest in either Tailored Talks or POGO Studio.

ATM and HYYC have no conflicts of interests to declare.

\section{Ethics approval and consent to participate}

Not applicable.

\section{Consent for publication}

Not applicable.

\section{Availability of data and materials}

The datasets used and/or analysed during the current study are available from the corresponding author on reasonable request.

\section{Competing interests}

The authors declare that they have no competing interests.

\section{Funding}


The funder of this study has no role in the design, data collection, reporting and interpretation and in writing the manuscript.

\section{Authors' contributions}

ATM drafted and wrote thepreceding and final versions of this manuscript. ATM developed the search strategy. HYYC, MD, and ATM contributed to the design of the study methodology and reviewed the final version of the manuscript. ATM screened titles and abstracts and HYYC screened abstracts as second reviewer. ATM performed methodological quality assessments, data extraction, data analyses.

\section{Acknowledgements}

Not applicable.

\section{References}

1. Snowdon AMM, Rosemary CK, Marion KC, Vikki AE, Adrian MG, Jonathan AC, et al. What influences recruitment to randomised controlled trials? A review of trials funded by two UK funding agencies. Trials. 2006;7(1):1-8.

2. Gul RAP. Clinical trials: the challenge of recruitment and retention of participants - Gul - 2010 - Journal of Clinical Nursing - Wiley Online Library. Journal of Clinical Nursing. 2009.

3. Frye JLP, Robert L. Strategies for Recruitment and Retention of Participants in Clinical Trials. JAMA. 2020;306(16):1798-9.

4. Nijhawan LP, Janodia MD, Muddukrishna BS, Bhat KM, Bairy KL, Udupa N, et al. Informed consent: Issues and challenges. J Adv Pharm Technol Res. 2013;4(3):134-40.

5. Mazzochi T. Individual Project Submission for Good Clinical Practice course. [Individual Project Submission for Good Clinical Practice, Regulatory and Ethics course]. In press 2019.

6. Orri M, Lipset CH, Jacobs BP, Costello AJ, Cummings SR. Web-based trial to evaluate the efficacy and safety of tolterodine ER 4mg in participants with overactive bladder: REMOTE trial. Contemp Clin Trials. 2014;38(2):190-7.

7. Isaksson E, Wester P, Laska A, Näsman P, Lundström E. Identifying important barriers to recruitment of patients in randomised clinical studies using a questionnaire for study personnel. BMC. 2019;20(618):1-8.

8. Agency HRAM, Healthcare products R. Joint statement on seeking consent by electronic methods 2018 [Available from:

https://www.hra.nhs.uk/media/documents/hra-mhra-econsent-statement-sept-18.pdf.

9. Chen C, Lee P-I, Pain KJ, Delgado D, Cole CL, Campion TR, Jr. Replacing Paper Informed Consent with Electronic Informed Consent for Research in Academic Medical Centers: A Scoping Review. AMIA Jt Summits Transl Sci Proc. 2020;2020:80-8.

10. Andrews L, Kostelecky K, Spritz S, Franco A. Virtual Clinical Trials: One Step Forward, Two Steps Back. Journal of Health Care Law and Policy. 2017;19(2):189-245.

11. Huys EDS, Evelien De S, Drieda Z, Stefania B, Maria Luisa Di P, David G, et al. Implementation of Electronic Informed Consent in Biomedical Research and Stakeholders' Perspectives: Systematic Review. J Med Internet Res 2020;22(10):e19129 https://wwwjmirorg/2020/10/e19129/. 2020.

12. Love S, Armstrong E, Bayliss C, Boulter M, Fox L, Grumett J, et al. Monitoring advances including consent: learning from COVID-19 trials and other trials running in UKCRC registered clinical trials units during the pandemic. BMC. 2021;22(279):1-10.

13. Research UCIOo. How To Consent 2020 [Available from: https://www.research.uci.edu/compliance/human-research-protections/researchers/how-toconsent.html.

14. Harmonisation ICo. Guideline for good clinical practice E6 (R2) 2016 [Available from: https://www.ema.europa.eu/en/documents/scientific-guideline/iche-6-r2-guideline-good-clinical-practice-step-5_en.pdf.

15. Pillay S. How much is too much information? The dose response curve of informed consent. 2017.

16. Bester J, Cole C, Kodish E. The Limits of Informed Consent for an Overwhelmed Patient: Clinicians' Role in Protecting Patients and Preventing Overwhelm. AMA Journal of Ethics. 2016;18(9):869-86.

17. Kadam RA. Informed consent process: A step further towards making it meaningful! Perspect Clin Res. 2017;8(3):107-12.

18. Us_Fda. Use of Electronic Informed Consent in Clinical Investigations - Questions and Answers | FDA. @US_FDA; 2021.

19. Federation EC. Electronic Informed Consent Implementation Guide Practical Considerations. 2021:1-27.

20. Healy P, Galvin S, Williamson PR, Treweek S, Whiting C, Maeso B, et al. Identifying trial recruitment uncertainties using a James Lind Alliance Priority Setting Partnership - the PRioRiTy (Prioritising Recruitment in Randomised Trials) study. Trials. 2018;19(1):147-.

21. Treweek S, Pitkethly M, Cook J, Fraser C, Mitchell E, Sullivan F, et al. Strategies to improve recruitment to randomised trials. Cochrane Database of Systematic Reviews. 2018(2).

22. Gardner HR, Albarquoni L, El Feky A, Gillies K, Treweek S. A systematic review of non-randomised evaluations of strategies to improve participant recruitment to randomised controlled trials. F1000Res. 2020;9:86-

23. Frampton GK, Shepherd J, Pickett K, Griffiths G, Wyatt JC. Digital tools for the recruitment and retention of participants in randomised controlled trials: a systematic map. Trials. 2020;21(1):478-

24. Blatch-Jones A, Nuttall J, Bull A, Worswick L, Mullee M, Peveler R, et al. Using digital tools in the recruitment and retention in randomised controlled trials: survey of UK Clinical Trial Units and a qualitative study. Trials. 2020;21(1):304-. 
25. Ryan RE, Prictor MJ, McLaughlin KJ, Hill SJ. Audio-visual presentation of information for informed consent for participation in clinical trials. Cochrane Database of Systematic Reviews. 2008;(1) (no pagination).

26. Duane S, Vellinga A, Smith V, Tierney M, Beecher C, Burke M, et al. The effectiveness of digital multimedia presentation of trial information on recruitment and retention of patients: Protocol for a study within a trial (SWAT). HRB Open Res. 2020;3:10-

27. Inc TB. TransCelerate - Pharmaceutical Research and Development 2020 [Available from: https://www.transceleratebiopharmainc.com/.

28. Initiative CTT. Informed Consent 2016 [Available from: https://www.ctti-clinicaltrials.org/projects/informed-consent.

29. Initiative IM. Innovative Medicines Initiative - Homepage: @IMI_JU; 2020 [Available from: http://www.imi.europa.eu/.

30. Guglielmo CCL. The Journey To Global eConsent Adoption: Where Do We Currently Stand? Free Clinical Lieader Newsletter. 2020.

31. Network E. Preferred Reporting Items for Systematic Reviews and Meta-Analyses: The PRISMA Statement | The EQUATOR Network 2021 [Available from: https://www.equator-network.org/reporting-guidelines/prisma/.

32. Treweek S, Bevan S, Bower P, Campbell M, Christie J, Clarke M, et al. Trial Forge Guidance 1: what is a Study Within A Trial (SWAT)? Trials. 2018;19(1):139.

33. Covidence. Covidence - Better systematic review management 2020 [Available from: https://www.covidence.org/.

34. Prisma. PRISMA Flow Diagram 2020 [Available from: http://prisma-statement.org/prismastatement/flowdiagram.aspx.

35. Higgins JP, Altman DG, Gøtzsche PC, Jüni P, Moher D, Oxman AD, et al. The Cochrane Collaboration's tool for assessing risk of bias in randomised trials. BMC. 2011;343:1-9.

36. Programme CAS. Critical Appraisal Skills Programme CASP Study Checklist. 2019.

37. Network E. Synthesis without meta-analysis (SWiM) in systematic reviews: reporting guideline I The EQUATOR Network equator-network.org2020 [Available from: https://www.equator-network.org/reporting-guidelines/synthesis-without-meta-analysis-swim-in-systematic-reviews-reporting-guideline/.

38. Snilstveit B, Oliver S, Vojtkova M. Narrative approaches to systematic review and synthesis of evidence for international development policy and practice. Journal of Development Effectiveness. 2012;4:409-29.

39. Haussen DC, Doppelheuer S, Schindler K, Grossberg JA, Bouslama M, Schultz M, et al. Utilization of a smartphone platform for electronic informed consent in acute stroke trials. Stroke. 2017;48(11):3156-60.

40. Rothwell E, Wong B, Rose NC, Anderson R, Fedor B, Stark LA, et al. A randomized controlled trial of an electronic informed consent process. Journal of empirical research on human research ethics : JERHRE. 2014;9(5):1-7.

41. Bobb MR, Van Heukelom PG, Faine BA, Ahmed A, Messerly JT, Bell G, et al. Telemedicine Provides Noninferior Research Informed Consent for Remote Study Enrollment: A Randomized Controlled Trial. Acad Emerg Med. 2016;23(7):759-65.

42. Dobscha SK, Corson K, Solodky J, Gerrity MS. Use of videoconferencing for depression research: Enrollment, retention, and patient satisfaction. Telemedicine Journal and e-Health. 2005;11(1):84-9.

43. Lurie JD, Spratt KF, Blood EA, Tosteson TD, Tosteson AN, Weinstein JN. Effects of viewing an evidence-based video decision aid on patients' treatment preferences for spine surgery. Spine. 2011;36(18):1501-4.

44. Swain S, Robinson BN, Newman AF, Tefera E, Herbolsheimer P, Nunes R, et al. Increasing participation in research-breast cancer (Inspire-BrC). Cancer Research Conference: 39th Annual CTRC AACR San Antonio Breast Cancer Symposium United States. 2017;77(4 Supplement 1).

45. Jolly K, Sidhu M, Bower P, Madurasinghe V. Improving recruitment to a study of telehealth management for COPD: a cluster randomised controlled 'study within a trial' (SWAT) of a multimedia information resource. Trials. 2019;20(1):453.

46. Mattock HC, Ryan R, O'Farrelly C, Babalis D, Ramchandani PG. Does a video clip enhance recruitment into a parenting trial? Learnings from a study within a trial. Trials. 2020;21(1).

47. Afolabi MO, McGrath N, D'Alessandro U, Kampmann B, Imoukhuede EB, Ravinetto RM, et al. A multimedia consent tool for research participants in the Gambia: A randomized controlled trial. Bulletin of the World Health Organization. 2015;93(5):320-8A.

48. Ditai J, Kanyago J, Nambozo MR, Odeke NM, Abeso J, Dusabe-Richards J, et al. Optimising informed consent for participants in a randomised controlled trial in rural Uganda: a comparative prospective cohort mixed-methods study. Trials. 2018;19(1):699.

49. Weston J, Hannah M, Downes J. Evaluating the benefits of a patient information video during the informed consent process. Patient Education and Counseling. 1997;30(3):239-45.

50. Barrera AZ, Dunn LB, Nichols A, Reardon S, Munoz RF. Getting It "Right". Journal of empirical research on human research ethics : JERHRE. $2016 ; 11(4): 291-8$.

\section{Tables}

Table 1 


\begin{tabular}{|c|c|c|c|c|c|c|c|c|c|}
\hline & & & & & & Type & Mode & & \\
\hline Study & Country & Design & $\begin{array}{l}\text { Target } \\
\text { clinical } \\
\text { group }\end{array}$ & Population & $\begin{array}{l}\text { Sample } \\
\text { Size }\end{array}$ & Intervention & & Comparator & Outcome \\
\hline $\begin{array}{l}\text { Afolabi- } \\
2015^{47}\end{array}$ & Gambia & Clinical Trial & Malaria & $\begin{array}{l}\text { Adults with } \\
\text { asymptomatic } \\
\text { malaria, }<50 \\
\text { years, more } \\
\text { than } 50 \% \\
\text { women with } \\
\text { no formal } \\
\text { education }\end{array}$ & 311 & Video & $\begin{array}{l}\text { In } \\
\text { person }\end{array}$ & $\begin{array}{l}\text { Paper } \\
\text { consent }\end{array}$ & Comprehension \\
\hline $\begin{array}{l}\text { Barrera- } \\
2016^{50}\end{array}$ & Worldwide & Observational & $\begin{array}{l}\text { Pregnant } \\
\text { women }\end{array}$ & $\begin{array}{l}\text { Pregnant } \\
\text { women, mean } \\
\text { age } 27.6 \\
\text { years, } 81.5 \% \\
\text { university } \\
\text { level } \\
\text { education }\end{array}$ & 1179 & $\begin{array}{l}\text { Online informed } \\
\text { consent }\end{array}$ & $\begin{array}{l}\text { In } \\
\text { person }\end{array}$ & None & Comprehension \\
\hline $\begin{array}{l}\text { Ditai- } \\
2018^{48}\end{array}$ & Uganda & Observational & $\begin{array}{l}\text { Pregnant } \\
\text { women }\end{array}$ & $\begin{array}{l}\text { Pregnant } \\
\text { women, no } \\
\text { mean age } \\
\text { reported, } 50 \% \\
\text { with no } \\
\text { formal } \\
\text { education }\end{array}$ & 30 & $\begin{array}{l}\text { Slide show using } \\
\text { illustrated text on } \\
\text { a flip chart or } \\
\text { video }\end{array}$ & $\begin{array}{l}\text { In } \\
\text { person }\end{array}$ & $\begin{array}{l}\text { Standard } \\
\text { researcher } \\
\text { read IC }\end{array}$ & $\begin{array}{l}\text { Comprehension } \\
\text { and recalling }\end{array}$ \\
\hline $\begin{array}{l}\text { Haussen- } \\
2017^{39}\end{array}$ & $\begin{array}{l}\text { United } \\
\text { States }\end{array}$ & Observational & Stroke & $\begin{array}{l}\text { Adults, mean } \\
\text { age } 73 \text { years }\end{array}$ & 4 & $\begin{array}{l}\text { DAWN trial: All } 3 \\
\text { components of IC } \\
\text { electronic. ARISE-II } \\
\text { method presumed } \\
\text { the same }\end{array}$ & Remote & $\begin{array}{l}\text { Paper } \\
\text { consent }\end{array}$ & $\begin{array}{l}\text { Description of } \\
\text { first experience } \\
\text { with electronic } \\
\text { consent }\end{array}$ \\
\hline $\begin{array}{l}\text { Rothwell- } \\
201440\end{array}$ & $\begin{array}{l}\text { United } \\
\text { States }\end{array}$ & Clinical Trial & $\begin{array}{l}\text { Women, } \\
\text { prenatal } \\
\text { education }\end{array}$ & $\begin{array}{l}\text { Female } \\
\text { participants, } \\
61 \% \text { had } \\
\text { given birth } \\
\text { before, } \\
41.94 \% \text { were } \\
\text { educated at a } \\
\text { bachelor's } \\
\text { degree }\end{array}$ & 62 & $\begin{array}{l}\text { Video on iPad as } \\
\text { an aid to paper } \\
\text { consent }\end{array}$ & $\begin{array}{l}\text { In } \\
\text { person }\end{array}$ & $\begin{array}{l}\text { Paper } \\
\text { consent }\end{array}$ & Comprehension \\
\hline $\begin{array}{l}\text { Bobb- } \\
2016^{41}\end{array}$ & $\begin{array}{l}\text { United } \\
\text { States }\end{array}$ & Clinical Trial & Pneumonia & $\begin{array}{l}\text { Adults, mean } \\
\text { age } 55,49 \% \\
\text { subjects were } \\
\text { male }\end{array}$ & 131 & $\begin{array}{l}\text { Telemedicine as } \\
\text { an aid to paper } \\
\text { consent }\end{array}$ & $\begin{array}{l}\text { In } \\
\text { person }\end{array}$ & $\begin{array}{l}\text { Paper } \\
\text { consent }\end{array}$ & Comprehension \\
\hline $\begin{array}{l}\text { Dobscha- } \\
2005^{42}\end{array}$ & $\begin{array}{l}\text { United } \\
\text { States }\end{array}$ & Observational & Depression & $\begin{array}{l}\text { Adults, } 87- \\
93 \% \text { male. } \\
\text { Mean age } \\
\text { varied from } \\
57 \text { to } 59\end{array}$ & 31 & $\begin{array}{l}\text { Videoconferencing } \\
\text { - all } 3 \text { components } \\
\text { electronic }\end{array}$ & Remote & $\begin{array}{l}\text { Paper } \\
\text { consent }\end{array}$ & $\begin{array}{l}\text { Description of } \\
\text { first experience } \\
\text { with electronic } \\
\text { consent - } \\
\text { Patient } \\
\text { satisfaction }\end{array}$ \\
\hline $\begin{array}{l}\text { Jolly- } \\
201945\end{array}$ & $\begin{array}{l}\text { United } \\
\text { Kingdom }\end{array}$ & Clinical Trial & COPD & $\begin{array}{l}\text { Adults, mostly } \\
\text { male, mean } \\
\text { age } 70 \text { years, } \\
\text { limited } \\
\text { educational } \\
\text { qualifications }\end{array}$ & 4214 & $\begin{array}{l}\text { Standard printed } \\
\text { materials with } \\
\text { access to a } \\
\text { multimedia } \\
\text { information } \\
\text { resource }\end{array}$ & Remote & $\begin{array}{l}\text { Paper } \\
\text { consent }\end{array}$ & $\begin{array}{l}\text { Recruitment } \\
\text { rate }\end{array}$ \\
\hline
\end{tabular}




\begin{tabular}{|c|c|c|c|c|c|c|c|c|c|}
\hline & & & & & & Type & Mode & & \\
\hline $\begin{array}{l}\text { Lurie- } \\
2011^{43}\end{array}$ & $\begin{array}{l}\text { United } \\
\text { States }\end{array}$ & Observational & $\begin{array}{l}\text { Spine } \\
\text { Surgery }\end{array}$ & $\begin{array}{l}\text { Adults with } \\
\text { IDH or SPS - } \\
\text { with or } \\
\text { without DS. } \\
\text { IDH mean age } \\
41.2-42 \text { years, } \\
\text { SPS mean } \\
\text { age } 65.1-67.1 \\
\text { years, IDH } \\
\text { female gender } \\
38-46 \% \text {, SPS } \\
\text { female gender } \\
42-52 \%) \text {. }\end{array}$ & 2505 & $\begin{array}{l}\text { Video decision aid } \\
\text { as part of their } \\
\text { informed consent } \\
\text { process }\end{array}$ & $\begin{array}{l}\text { In } \\
\text { person }\end{array}$ & $\begin{array}{l}\text { Before and } \\
\text { after } \\
\text { viewing } \\
\text { video }\end{array}$ & $\begin{array}{l}\text { Changes in } \\
\text { treatment } \\
\text { preference }\end{array}$ \\
\hline $\begin{array}{l}\text { Swain- } \\
2017^{44}\end{array}$ & $\begin{array}{l}\text { United } \\
\text { States }\end{array}$ & Observational & $\begin{array}{l}\text { Breast } \\
\text { cancer }\end{array}$ & $\begin{array}{l}\text { Adults with } \\
\text { breast cancer, } \\
\text { mean age } 59 \\
\text { years, 29\% } \\
\text { attended } \\
\text { college or } \\
\text { technical } \\
\text { school. }\end{array}$ & 200 & Video & $\begin{array}{l}\text { In } \\
\text { person }\end{array}$ & None & $\begin{array}{l}\text { Recruitment } \\
\text { rate }\end{array}$ \\
\hline $\begin{array}{l}\text { Weston- } \\
1997^{49}\end{array}$ & Canada & Clinical Trial & $\begin{array}{l}\text { Pregnant } \\
\text { women }\end{array}$ & $\begin{array}{l}\text { Pregnant } \\
\text { women, } \\
\text { median } \\
\text { maternal age } \\
31.4-31.8 \\
\text { years, median } \\
\text { gestation in } \\
\text { weeks } 25 \\
-27.3,40-42 \% \\
\text { college degree } \\
\text { or higher }\end{array}$ & 90 & Video & $\begin{array}{l}\text { In } \\
\text { person }\end{array}$ & $\begin{array}{l}\text { Paper } \\
\text { consent }\end{array}$ & $\begin{array}{l}\text { Willigness for } \\
\text { future } \\
\text { participation in } \\
\text { a trial }\end{array}$ \\
\hline
\end{tabular}

Table 2. Summary of Study Outcomes 
Mean age

\section{Primary Outcome - Effect on enrolment}

\begin{tabular}{|c|c|c|c|c|}
\hline $\begin{array}{l}\text { Bobb } \\
2016^{41}\end{array}$ & $\begin{array}{l}\mathrm{n}=131 \\
\text { Mean } \\
\text { age }=55\end{array}$ & $\begin{array}{l}\text { Not } \\
\text { assessed }\end{array}$ & Telemedicine & $\begin{array}{l}\text { No improvement. Computer-enabled audio- } \\
\text { visual communication as an aid to paper } \\
\text { consent vs written IC:56\% vs. } 69 \%, p=0.142\end{array}$ \\
\hline $\begin{array}{l}\text { Jolly } \\
201945\end{array}$ & $\begin{array}{l}\mathrm{N}=4214 \\
\text { Mean } \\
\text { age }=70\end{array}$ & $\begin{array}{l}\text { No formal } \\
\text { education }\end{array}$ & $\begin{array}{l}\text { Standard } \\
\text { printed } \\
\text { material with } \\
\text { access to } \\
\text { multimedia } \\
\text { information } \\
\text { resource }\end{array}$ & $\begin{array}{l}\text { No improvement. Written IC with access to } \\
\text { multimedia resource vs written IC: OR } 0.84,95 \% \\
\text { CI } 0.58 \text { to } 1.22\end{array}$ \\
\hline $\begin{array}{l}\text { Mattock } \\
202046\end{array}$ & $\begin{array}{l}\mathrm{N}=107 \\
\text { Mean } \\
\text { parent } \\
\text { age=33.59 } \\
\text { Mean } \\
\text { child } \\
\text { age=21.9 } \\
\text { months }\end{array}$ & $\begin{array}{l}47 \% \\
\text { educated at } \\
\text { postgraduate } \\
\text { level }\end{array}$ & $\begin{array}{l}\text { Information } \\
\text { video as an } \\
\text { aid to patient } \\
\text { information } \\
\text { sheet }\end{array}$ & $\begin{array}{l}\text { Intervention group less likely to take part in } \\
\text { main clinical trial . Video aid to paper } \mathrm{v} \text { written } \\
\mathrm{IC}: \mathrm{OR}=0.25, \mathrm{Cl}=0.10-0.62, \mathrm{p}=0.003\end{array}$ \\
\hline $\begin{array}{l}\text { Swain } \\
2017^{44}\end{array}$ & $\begin{array}{l}\mathrm{N}=200 \\
\mathrm{Mean} \\
\text { age }=59\end{array}$ & $\begin{array}{l}29 \% \\
\text { attended } \\
\text { some college } \\
\text { or technical } \\
\text { school }\end{array}$ & $\begin{array}{l}\text { Educational } \\
\text { video }\end{array}$ & $\begin{array}{l}\text { Improvement on enrolment by } 7 \% \text { post- } \\
\text { intervention }(13.5 \% \text { of } 200 \text { participants enrolled } \\
\text { post-intervention, } 6 \% \text { enrolled pre-intervention, } \\
p<0.001)\end{array}$ \\
\hline $\begin{array}{l}\text { Weston } \\
1997^{49}\end{array}$ & $\begin{array}{l}\mathrm{N}=90 \\
\text { Median } \\
\text { age }=31.4\end{array}$ & $\begin{array}{l}40-42 \% \\
\text { achieved } \\
\text { college } \\
\text { degree or } \\
\text { higher }\end{array}$ & $\begin{array}{l}\text { Information } \\
\text { video }\end{array}$ & $\begin{array}{l}\text { Improvement on participants expressing } \\
\text { willingness to participate in a future trial }(61.9 \% \\
\text { vs. } 35.4 \%, x 2=6.3 ; \mathrm{df}=1 ; \mathrm{P}=0.01)\end{array}$ \\
\hline
\end{tabular}

Secondary Outcomes

\section{Effect on economic costs}

\begin{tabular}{lllll}
$\begin{array}{l}\text { Afolabi } \\
2015^{47}\end{array}$ & $\begin{array}{l}\mathrm{N}=311 \\
\text { Mean } \\
\text { age=NA }\end{array}$ & $\begin{array}{l}>50 \% \text { no } \\
\text { formal } \\
\text { education }\end{array}$ & $\begin{array}{l}\text { Video } \\
\text { information }\end{array}$ & No results available \\
\hline Jolly & $\begin{array}{l}\mathrm{N}=4214 \\
\text { Mean } \\
\text { age=70 }\end{array}$ & $\begin{array}{l}\text { No formal } \\
\text { education }\end{array}$ & $\begin{array}{l}\text { Standard } \\
\text { printed } \\
\text { material with }\end{array}$ & $\begin{array}{l}\text { Additional six people would be recruited per } \\
1000 \text { approached at a cost of } £ 100 \text { per } \\
\text { additional patient with the use of an online }\end{array}$ \\
$\begin{array}{l}\text { access to } \\
\text { multimedia } \\
\text { information } \\
\text { resource }\end{array}$ & $\begin{array}{l}\text { multimedia intervention. The cost of the online } \\
\text { multimedia intervention was estimated } £ 2500\end{array}$ \\
& & & \\
\end{tabular}

Patient comprehension \& understanding

\begin{tabular}{|c|c|c|c|c|c|}
\hline $\begin{array}{l}\text { Afolabi } \\
2015^{47}\end{array}$ & $\begin{array}{l}\mathrm{N}=311 \\
\text { Mean } \\
\text { age=NA }\end{array}$ & $\begin{array}{l}>50 \% \text { no } \\
\text { formal } \\
\text { education }\end{array}$ & $\begin{array}{l}\text { Video } \\
\text { information }\end{array}$ & $\begin{array}{l}\text { Improvement. Score at day } 14: 64 \% \text { v } 40 \% \text {, } \\
p=0.035\end{array}$ & \\
\hline $\begin{array}{l}\text { Barrera } \\
2016^{50}\end{array}$ & $\begin{array}{l}N=1179 \\
\text { Mean } \\
\text { age }=27.6\end{array}$ & $\begin{array}{l}81.5 \% \\
\text { University } \\
\text { level }\end{array}$ & Online IC & $\begin{array}{l}\text { Improvement. Correct understanding of the } \\
\text { study's purpose ( } 86.1 \%) \text { and correctly identified } \\
\text { two of three of the study's benefits ( } 74.6 \%) \text {. } 56 \% \\
\text { correctly identified some or all of the potential } \\
\text { risks of participation }\end{array}$ & $\begin{array}{l}\text { Qualitative interviews in this study } \\
\text { supported that the video was easy to } \\
\text { understand and improved participants' } \\
\text { attention }\end{array}$ \\
\hline $\begin{array}{l}\text { Bobb } \\
2016^{41}\end{array}$ & $\begin{array}{l}\mathrm{N}=131 \\
\mathrm{Mean} \\
\text { age }=55\end{array}$ & $\begin{array}{l}\text { Not } \\
\text { assessed }\end{array}$ & Telemedicine & $\begin{array}{l}\text { Not inferior to standard face-to-face written } \\
\text { consent, measured using a modified quality of } \\
\text { informed consent instrument (QuIC) (QulC } \\
\text { scores } 74.4 \pm 8.1 \text { vs. } 74.4 \pm 6.9 \text { on a 100-point } \\
\text { scale, } p=0.999 \text { ) }\end{array}$ & \\
\hline $\begin{array}{l}\text { Ditai } \\
2018^{48}\end{array}$ & $\begin{array}{l}\mathrm{N}=30 \\
\text { Mean } \\
\text { age=NA }\end{array}$ & $\begin{array}{l}50 \% \text { no } \\
\text { formal } \\
\text { education }\end{array}$ & $\begin{array}{l}\text { Slide show } \\
\text { using } \\
\text { illustrated } \\
\text { text on a flip } \\
\text { chart }\end{array}$ & $\begin{array}{l}\text { No statistically significant difference on the } \\
\text { QulC tool at } 48 \text { hours after consenting to any of } \\
\text { the three models of IC }\end{array}$ & $\begin{array}{l}\text { Most participants preferred the slide- } \\
\text { show message }(63 \%, 19 / 30) \text {, compared } \\
\text { with } 20 \%(6 / 30) \text { for the video message } \\
\text { and } 17 \%(5 / 30) \text { for the standard } \\
\text { model. }\end{array}$ \\
\hline
\end{tabular}




$\begin{array}{llll}\text { Rothwell } & \mathrm{N}=62 & \begin{array}{l}41.94 \% \\ \text { bachelor's }\end{array} & \text { Video } \\ 20144^{40} & \begin{array}{l}\text { Mean } \\ \text { age=NA }\end{array} & \begin{array}{l}\text { degree } \\ \end{array} & \end{array}$

$\begin{array}{llll}\text { Weston } & \begin{array}{l}\text { N=90 } \\ \text { Median }\end{array} & \begin{array}{l}\text { 40-42\% } \\ \text { ache }=31.4\end{array} & \begin{array}{l}\text { Information } \\ \text { college } \\ \text { degree or } \\ \text { vigher }\end{array} \\ & \end{array}$

Improve understanding of some aspects of a trial: "the alternatives to participation in this study" (4.88 \pm 0.42 vs. $4.37 \pm 1.10, p=.047)$; "who to contact if you are upset because of participation in this study" (4.41 \pm 0.80 vs. 4.03 $\pm 1.40, p=.002$ ); "Whom you should contact if you have questions or concerns about this study" (4.34 \pm 0.97 vs. $4.13 \pm 1.33, p=.009)$; and "Overall, how well did you understand this study when you signed the consent form" (4.72 \pm 0.58 vs. $4.63 \pm 0.67, p=.019$ )

no differences in knowledge about the perinatal trial after receiving a video intervention when compared to written IC but they did find an increase in the retention of knowledge 2-4 weeks later by women in the video intervention group

\section{Acceptability to participants}

\begin{tabular}{|c|c|c|c|c|}
\hline $\begin{array}{l}\text { Mattock } \\
2020^{46}\end{array}$ & $\begin{array}{l}\mathrm{N}=107 \\
\text { Mean } \\
\text { parent } \\
\text { age=33.59 } \\
\text { Mean } \\
\text { child } \\
\text { age=21.9 } \\
\text { months }\end{array}$ & $\begin{array}{l}47 \% \\
\text { educated at } \\
\text { postgraduate } \\
\text { level }\end{array}$ & $\begin{array}{l}\text { Information } \\
\text { video as an } \\
\text { aid to patient } \\
\text { information } \\
\text { sheet }\end{array}$ & $\begin{array}{l}\text { Positive feedback. Information easy to } \\
\text { understand and informative but also } \\
\text { commented on additional questions that } \\
\text { needed discussing over the phone. }\end{array}$ \\
\hline
\end{tabular}

\begin{tabular}{|c|c|c|c|c|}
\hline $\begin{array}{l}\text { Haussen } \\
2017^{39}\end{array}$ & $\begin{array}{l}\mathrm{N}=4 \text { Mean } \\
\text { age }=73\end{array}$ & $\begin{array}{l}\text { Not } \\
\text { assessed }\end{array}$ & $\begin{array}{l}\text { All } 3 \\
\text { components } \\
\text { electronic for } \\
\text { DAWN trial. } \\
\text { Method for } \\
\text { ARISE-I } \\
\text { presumed } \\
\text { the same }\end{array}$ & $\begin{array}{l}\text { Acceptability of the use of an entirely electronic } \\
\text { IC process to remotely obtain IC from the legally } \\
\text { authorized representative (LAR) of stroke } \\
\text { patients being enrolled into a clinical trial of } \\
\text { neurointervention }\end{array}$ \\
\hline $\begin{array}{l}\text { Bobb } \\
2016^{41}\end{array}$ & $\begin{array}{l}\mathrm{N}=131 \\
\mathrm{Mean} \\
\text { age }=55\end{array}$ & $\begin{array}{l}\text { Not } \\
\text { assessed }\end{array}$ & Telemedicine & $\begin{array}{l}\text { No significant barriers in the use of } \\
\text { telemedicine (computer-enabled audio-visual } \\
\text { communication) as an aid to paper consent } \\
\text { from its qualitative survey. It reported that video } \\
\text { was easy to understand and was better at } \\
\text { holding patient's attention than a paper-based } \\
\text { approach would have. }\end{array}$ \\
\hline
\end{tabular}

\section{Changes in treatment preferences}

\begin{tabular}{|c|c|c|c|c|}
\hline $\begin{array}{l}\text { Lurie } \\
201143\end{array}$ & $\begin{array}{l}\mathrm{N}=2505 \\
\text { Mean } \\
\text { age=IDH } \\
41.2, \text { SPS } \\
65.1\end{array}$ & $\begin{array}{l}\text { No } \\
\text { difference in } \\
\text { education } \\
\text { attainment }\end{array}$ & $\begin{array}{l}\text { Video as an } \\
\text { aid to the IC }\end{array}$ & $\begin{array}{l}\text { Watching video information prior to enrollment } \\
\text { to a clinical trial comparing surgical and non- } \\
\text { surgical treatments for spinal diseases led to a } \\
\text { shift in treatment preference compared to non- } \\
\text { watchers }(37.9 \% \text { vs } 20.8 \% \text {, } p<0.0001)\end{array}$ \\
\hline
\end{tabular}

Invitation response and retention

\begin{tabular}{|c|c|c|c|c|}
\hline $\begin{array}{l}\text { Jolly } \\
201945\end{array}$ & $\begin{array}{l}\mathrm{N}=4214 \\
\text { Mean } \\
\text { age }=70\end{array}$ & $\begin{array}{l}\text { No formal } \\
\text { education }\end{array}$ & $\begin{array}{l}\text { Standard } \\
\text { printed } \\
\text { material with } \\
\text { access to } \\
\text { multimedia } \\
\text { information } \\
\text { resource }\end{array}$ & $\begin{array}{l}\text { No effect on the proportion of people } \\
\text { responding to study invitation (OR }=1.02,95 \% \\
\mathrm{Cl} 0.79 \text { to } 1.33 \text { ) or retention in the trial at } 6 \text { (ORs } \\
0.84,95 \% \mathrm{Cl} 0.57 \text { to } 1.22 \text { ) and } 12 \text { months after } \\
\text { randomisation }\end{array}$ \\
\hline $\begin{array}{l}\text { Swain } \\
2017^{44}\end{array}$ & $\begin{array}{l}\mathrm{N}=200 \\
\text { Mean } \\
\text { age }=59\end{array}$ & $\begin{array}{l}29 \% \\
\text { attended } \\
\text { some college } \\
\text { or technical } \\
\text { school }\end{array}$ & $\begin{array}{l}\text { Educational } \\
\text { video }\end{array}$ & $\begin{array}{l}\text { Increase by } 14 \%(\mathrm{p}<.001) \text { in the proportion of } \\
\text { patients expressing likelihood to enroll in a trial } \\
\text { for breast cancer after the use of an } \\
\text { educational video }\end{array}$ \\
\hline
\end{tabular}

Intervention Fidelity

Jolly N $\quad \mathrm{N}=4214 \quad$ No formal Standard Number of participants who used the link to

Comprehension not inferior to standard face-to-face written consent (QulC scores $74.4 \pm 8.1$ vs. $74.4 \pm 6.9$ on a 100 -point scale, $p=0.999$ ). 


\begin{tabular}{|c|c|c|c|c|}
\hline $2019^{45}$ & $\begin{array}{l}\text { Mean } \\
\text { age=70 }\end{array}$ & education & $\begin{array}{l}\text { printed } \\
\text { material with } \\
\text { access to } \\
\text { multimedia } \\
\text { information } \\
\text { resource }\end{array}$ & $\begin{array}{l}\text { access the multimedia resource which was part } \\
\text { of the intervention was not reported, so it was } \\
\text { unclear how many participants actually used } \\
\text { the resource }\end{array}$ \\
\hline $\begin{array}{l}\text { Mattock } \\
202046\end{array}$ & $\begin{array}{l}\mathrm{N}=107 \\
\text { Mean } \\
\text { parent } \\
\text { age=33.59 } \\
\text { Mean } \\
\text { child } \\
\text { age=21.9 } \\
\text { months }\end{array}$ & $\begin{array}{l}47 \% \\
\text { educated at } \\
\text { postgraduate } \\
\text { level }\end{array}$ & $\begin{array}{l}\text { Information } \\
\text { video as an } \\
\text { aid to patient } \\
\text { information } \\
\text { sheet }\end{array}$ & $\begin{array}{l}\text { Utilized an entire remote e-IC process to obtain } \\
\text { IC from LAR. However, it was not possible to } \\
\text { ascertain whether the LAR actually read the } \\
\text { online IC. It was unclear how much time the } \\
\text { LARs or patients were given to decide about } \\
\text { trial participation }\end{array}$ \\
\hline
\end{tabular}

Table 3 is available in the Supplemental Files section.

\section{Figures}

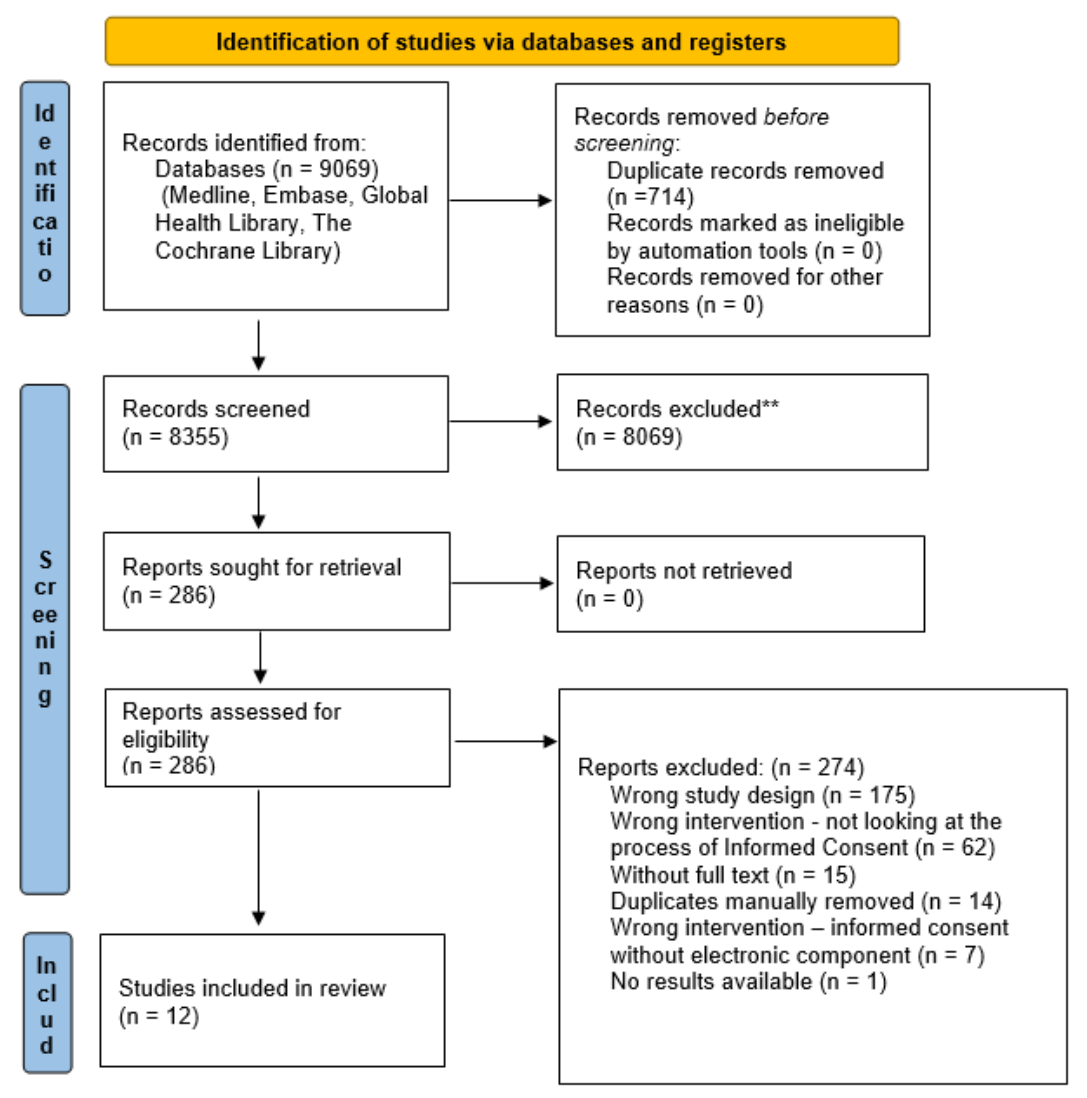

Figure 1

Prisma Flow Diagram for this systematic review 


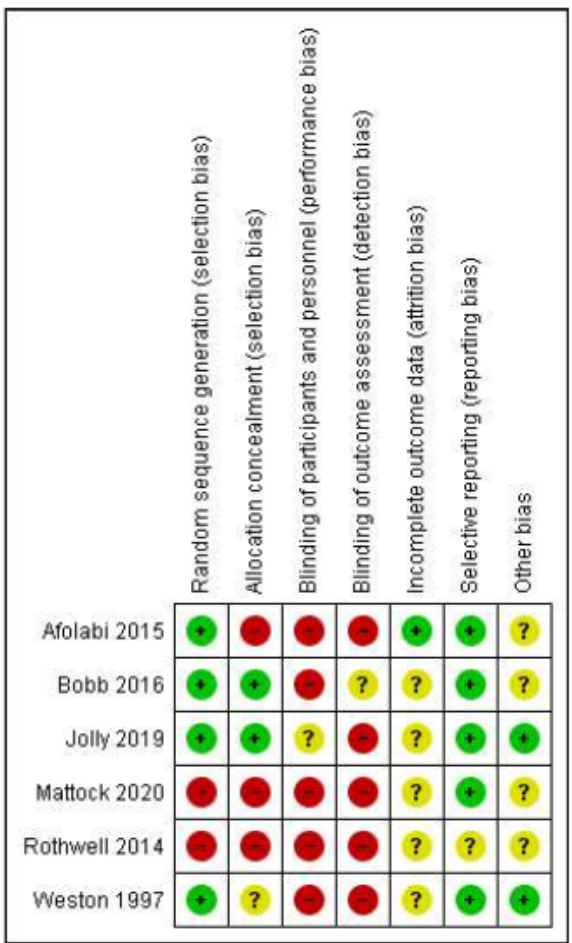

Figure 2

Risk of bias summary: Author's assessment of risk of bias for each included clinical trial. Red $=$ high risk, Yellow $=$ unclear risk, Green $=$ low risk

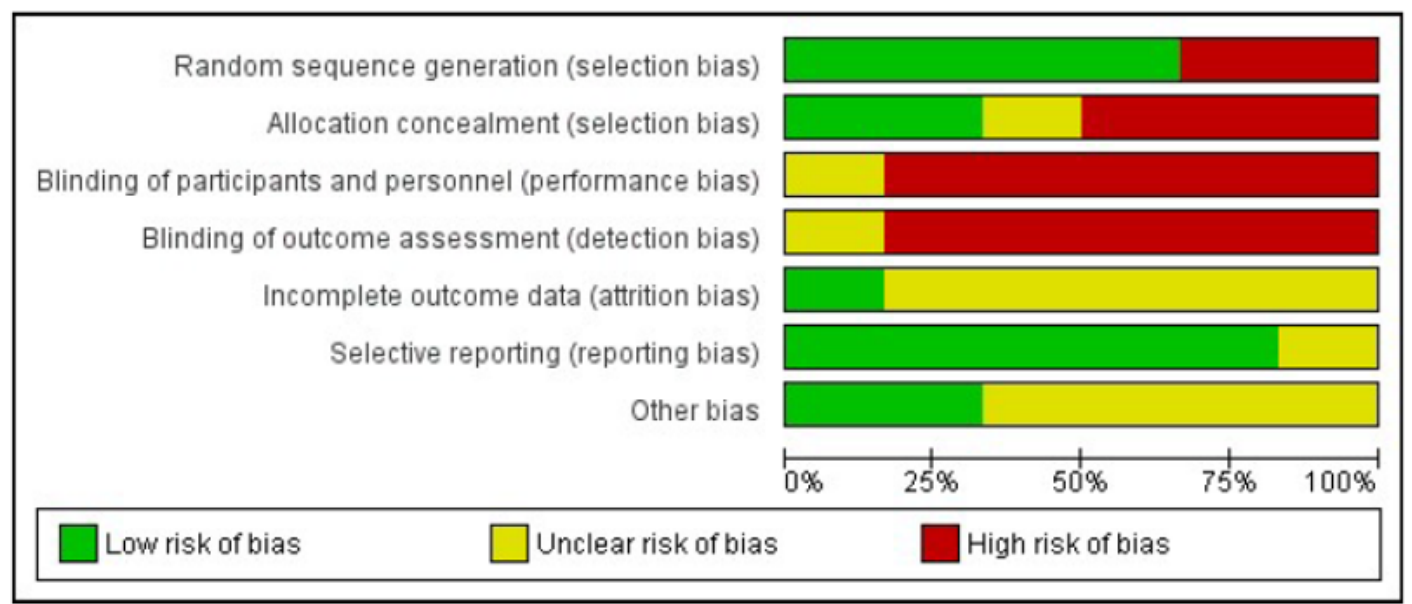

Figure 3

Risk of bias bar chart: Author's assessment of risk of bias for each included clinical trial expressed as percentages. Red $=$ high risk, Yellow $=$ unclear risk, Green $=$ low risk

\section{Supplementary Files}

This is a list of supplementary files associated with this preprint. Click to download.

- PRISMA2020checklist.docx

- Tablesfiguresappendices.docx 